\title{
Influence of substratum heterogeneity scales and complexity on a temperate epibenthic marine community
}

\author{
Louise Lapointe, Edwin Bourget*
}

GIROQ, Département de biologie, Université Laval, Ste-Foy, Québec G1K 7P4, Canada

\begin{abstract}
The influence of 4 scales of substratum heterogeneity on the establishment of a temperate sessile marine epibenthic community (Beaufort, North Carolina, USA) was examined over a period of $1 \mathrm{yr}$. Artificial panels with crevices representing 4 scales of heterogeneity of $0,1,10$ and $100 \mathrm{~mm}$ and with combinations of these crevices representing 4 levels of complexity $(0+1+10,0+1+100$, $0+10+100$ and $0+1+10+100 \mathrm{~mm}$ ) were deployed in January 1991 and sampled in March, June, September 1991, and January 1992. Significant temporal changes in abundance (\% cover) and species dominance were observed during each sample period. Initially (within 5 mo after immersion), significantly lower abundances occurred on panels with the $1 \mathrm{~mm}$ scale compared with panels without this scale. Changes in diversity appeared to be related mainly to the $100 \mathrm{~mm}$ scale of heterogeneity regardless of the complexity level: diversity values found on panels which included the $100 \mathrm{~mm}$ crevices were initially low, but exceeded that of all other panels by January (1 yr after immersion). In summary, panel complexity was not the major factor influencing community structure, but the scale of heterogeneity $(1 \mathrm{~mm}$ for abundances and $100 \mathrm{~mm}$ for diversity) had important and significant effects. These results indicate the specific importance of the $1 \mathrm{~mm}$ scale not only during the larval settlement phase but also during the development of the community. We compared these results with laboratory experiments using inert particles and similar panels, whose results suggest that larval behaviour is involved in the selection of settlement sites
\end{abstract}

KEY WORDS: Substratum heterogeneity - Substratum complexity · Epibenthic marine community Larval behaviour - Intertidal

\section{INTRODUCTION}

Substratum heterogeneity has long been known to influence larval settlement of marine epibenthic invertebrates (Crisp \& Barnes 1954, Barnes 1956, Crisp 1974, Bergeron \& Bourget 1986, Bourget 1988, Chabot \& Bourget 1988), but recent studies have emphasized the potential importance of microhabitat selection of larvae in structuring the developing community (Keough \& Downes 1982, Walters 1992, Underwood \& Chapman 1996, Hills \& Thomason 1998). The influence of substratum heterogeneity (grooves of different size or scale) and complexity (combinations of scale) on the early establishment of a northern community in the

•E-mail: edwin.bourget@fsg.ulaval.ca
Bay of Fundy, Eastern Canada, has been examined by Bourget et al. (1994). They found that both substratum heterogeneity and complexity had little influence on diversity and abundance during the early phases of community development $(3 \mathrm{mo})$, but controlled the small-scale distribution of species. The influence of the same scales of heterogeneity and complexity on the settlement of Tubularia and Balanus sp. larvae was examined in a temperate environment by Lemire \& Bourget (1996). The study confirmed that (1) larvae of both species exhibited settlement preferences with respect to scales of topographic heterogeneity $(0,1,10$ and $100 \mathrm{~mm} \mathrm{~V}$-shaped grooves), (2) these preferences were modified by substratum complexity (combinations of scales of heterogeneity), and (3) they were mediated by larval behaviour directly on or near the 
substratum (benthic behaviour after initial contact with the substratum). Grégoire et al. (1996), using inert polyvinylchloride particles (PVC) and the same experimental panels in a laboratory flume, examined whether hydrodynamics could generate the patterns of small-scale distribution observed in the field, and showed that the density of adhering particles decreased with increasing panel complexity. Thus, there are indications that substratum heterogeneity and complexity influence the early structure of nearshore benthic communities, at least in northern, and possibly in temperate environments.

Using the same experimental approach, the present study tests the hypothesis that the structure of a temperate epibenthic community is modified by substratum heterogeneity and complexity in both early and late successional stages. The importance of substratum heterogeneity becomes is important because it becomes pointless to examine short-term or small-scale patterns of settlement in order to predict the abundance and diversity of a community if, in the long run, these variables do not significantly alter the outcome of community structure.

The succession of benthic species through the processes of competition, predation and mutualism has become well known (Connell 1975, 1983, Schoener 1983, Roughgarden 1983, Dayton 1984, Underwood \& Denley 1984), so much so that a new approach ('supply side ecology') has emerged in recent years. This approach aims at predicting the trajectory of population development either from the percentage of free space on a given substratum, or from larval abundances in the plankton (Lewin 1986, Roughgarden et al. 1987, Le Fèvre \& Bourget 1991, 1992, Gaines \& Bertness 1992, Grosberg \& Levitan 1992, Miron et al. 1995). This procedure is only one step from predicting community structure from initial population abundance on a substratum given knowledge of the relative competitive ability of each species

In recent years, small-scale topography, hitherto unconsidered as a predictor variable, has been shown to considerably influence larval settlement patterns, particularly through its effect on local or boundary layer. hydrodynamics (Eckman 1983, Mullineaux \& Butman 1991, Harvey et al. 1995, Bourget \& Harvey 1998). In a heterogeneity range between $<0.5$ and $4 \mathrm{~mm}$. Hills \& Thomason (1998) have shown that settlement density of barnacle Semibalanus balanoides was higher on tiles with a heterogeneity of less than $0.5 \mathrm{~mm}$. By comparing large- and small-scale heterogeneity (approx. $\mathrm{mm}, \mathrm{cm}$ and $\mathrm{km}$ ), some recent field experiments have shown that small-scale substratum heterogeneity $(\mathrm{mm})$ plays a major role in determining the biomass and diversity of subarctic benthic communities (Archambault \& Bourget 1996, Blanchard \& Bourget 1999), with little evidence for large-scale impact ( $\mathrm{km}$, coastal contour). Underwood \& Chapman (1996), however, have pointed out the importance of small- ( $\mathrm{cm}$ or 1 to $2 \mathrm{~m}$ ) or large-scale (hundreds of meters) in explaining the variability in abundance of many species in New South Wales, Australia. Thus, the questions of whether topographic heterogeneity and complexity influence initial settlement and subsequent community developments, and if so, which scales are significant, are central to benthic community ecology. This study examines the overall effect of small-scale $(<10 \mathrm{~cm})$ substratum heterogeneity and complexity on the abundance, dominance and species diversity over the 1st yr of development of a temperate epibenthic community.

\section{METHODS}

The experiments were carried out under a raft near the Duke University Marine Laboratory, in Beaufort, North Carolina, USA, between January 1991 and January 1992. In January 1991, 64 dark grey PVC (polyvinyl chloride) panels $(30 \times 15 \mathrm{~cm})$ were attached vertically to the raft, in 8 groups, each including 1 of 8 panel types (Fig. 1). The panels were mechanically grooved (small scales: 1 and $10 \mathrm{~mm}$ ) using specially crafted blades, and could thus be precisely replicated (see Bourget et al. 1994). Larger scale panels (100 mm) were obtained by attaching together, using tie raps, precut portions of panels, either smooth or grooved. Each panel was sandblasted ( $<0.75 \mathrm{~mm}$ grit) to remove the glossy finish from the PVC. Three groove sizes of 1 , 10 and $100 \mathrm{~mm}$ (representing 3 scales of heterogeneity) and flat surfaces were arranged in all possible individual or nested combinations of scales (the latter representing 7 scales of complexity) (Fig. 1). The resulting 8 panel types were panel type $A$, smooth without grooves (representing the 1st order of complexity), panel types $B(0+1 \mathrm{~mm}), \mathrm{C}(0+10 \mathrm{~mm})$ and $\mathrm{D}(0+$ $100 \mathrm{~mm}$ ), which included 2 different scales of heterogeneity (representing the 2nd order of complexity), panel types $\mathrm{E}(0+1+10 \mathrm{~mm}), \mathrm{F}(0+1+100 \mathrm{~mm})$ and $\mathrm{G}(0+10+100 \mathrm{~mm})$, which included 3 scales of heterogeneity each (3rd order of complexity), and panel type $H$. which included all groove sizes $(0+1+10+$ $100 \mathrm{~mm}$ ) and was the most complex (4th order of complexity).

The 8 panel types (treatments) were deployed in a Latin square design to control for the possible confounding effects of current. Each line and column of the $8 \times 8$ Latin square was formed with 1 replicate of the 8 treatments (Fig. 2). Panels of each column were attached to a PVC pipe, treated as another variable ('supporting frame') in the analysis. All the panels were submerged $30 \mathrm{~cm}$ below the water surface. 


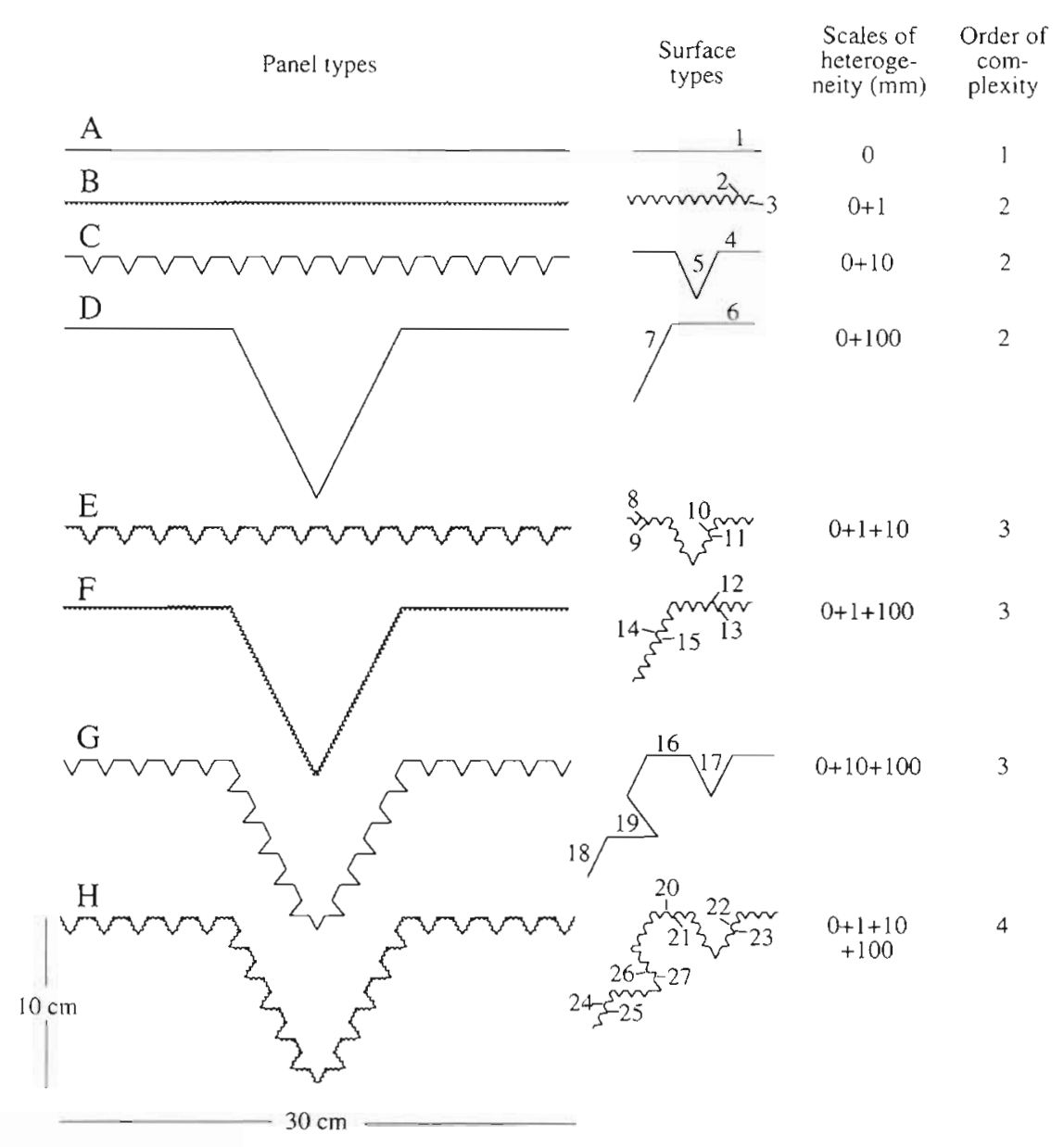

Fig. 1 The 8 panel types (A to $\mathrm{H}$ ) with their corresponding surface types ( 1 to 27 ) used in the experiment. The order of complexity corresponds to the number of scales of heterogeneity present on each panel type

Measurements were made in March, June and September 1991. In January 1992, the panels were reexamined for the effect of panel types only (see below). About 3 wk were needed to examine all the panels. To prevent continuing settlement over this period, all panels were removed from the sea at the beginning of each sampling period and placed in 3 outside pools supplied with continuous filtered seawater flow. For sampling, each of the 8 panels from a given supporting frame, selected at random, were brought into the laboratory and kept in a tank. Consequently, panel manipulations and current effects are confounded in this Latin square design and hereafter referred to as 'supporting frame' effects

Percent cover of all sessile species was evaluated at the scale of (1) the whole panel to characterize the effects of complexity of the panels, and (2) the smallest surface type inside each panel type (for panels $B$ to $H)$, to examine the effect of different scales of heterogeneity. A non-destructive, random-dot technique (Brault \& Bourget, 1985) was used for these 2 types of sampling. For the overall panel effect, percent cover was estimated using quadrats $(20 \times 10 \mathrm{~cm})$ with 100 random points marked on transparent films which were placed over the centre of each panel to avoid border effects $(5 \times 2.5 \mathrm{~cm})$. Sessile organisms which settled under the dots were identified to species or genus and counted. Percent covers $>100 \%$ were possible due to epizooic overgrowth. Whole panel diversity $\left(\bar{H}^{\prime}\right)$ was also calculated from these data using the Shannon-Wiener index $\left(\log _{2}\right)$. A total of 27 different surface types were identified on the 8 different panel types (Fig. 1). Four replicates of each surface type were sampled on each panel. Each surface type was evaluated using 20 dots randomly distributed along a $20 \mathrm{~cm}$ line transect on a transparent film. Positions of transects were also determined at random from all $1 \mathrm{~mm}$ positions possible on a given panel. Again, $5 \mathrm{~cm}$ on each side of the panel (length $=30 \mathrm{~cm}$ ) remained unsampled to prevent border effects. Transects were placed along the individual surfaces and organisms touching the dots were 


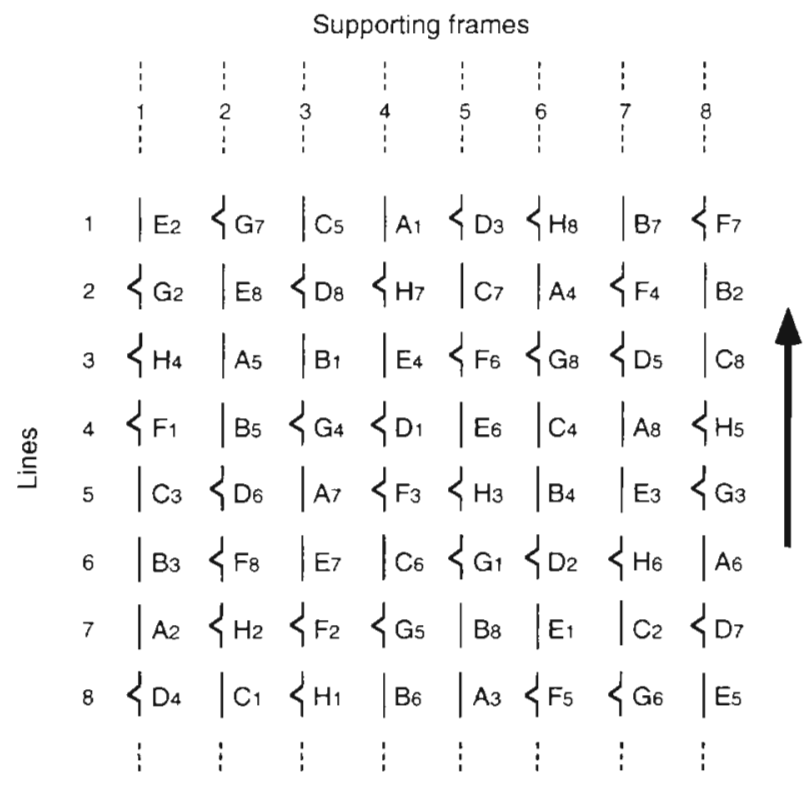

Fig. 2. The 64 panels arranged in a Latin square design. They were attached under a raft located in a narrow inlet. $\mathrm{A}$ to $\mathrm{H}$ indicates the panel types. Dashed lines represent the PVC pipes on which the panels were suspended. Arrow indicates predominant direction of residual currents

counted. A count $>20$ organisms was possible due to epizooic overgrowth

In June and September an extensive sampling was carried out to examine fine-scale distributions within the $100 \mathrm{~mm}$ crevices. Visual examination of the panels suggested community differences between the top and the bottom of the $100 \mathrm{~mm}$ crevices. Therefore, these crevices were divided into 2 parts. Four replicates of each surface type were sampled within each part, thus doubling the standard number of samples per surface type. Since no significant differences were detected between the top and bottom halves of the same crevice, the 8 replicates were used and, consequently, in June and September the number of replicate surfaces inside the $100 \mathrm{~mm}$ crevice was twice that for March and the other surface types (see df in Table 4 for June and September).

Because panels were sampled over time, repeated measures MANOVA were carried out on the Latin square design. For both abundance and diversity variables, normality (Shapiro-Wilk statistic, p > 0.05), homogeneity of variances (multivariate Bartlett test, $\chi^{2}=73.3, p=0.37$, and $\chi^{2}=77.7, p=0.25$ respectively) and the sphericity assumption of the multivariate approach (Mauchly's criterion, $\chi^{2}=10.11, p=0.07$ and $\chi^{2}=7,68, p=0.18$ respectively) were all respected. Hence, as the univariate analyses are more powerful than the multivariate approaches (repeated measures) when these criteria are re- spected (Girden 1992), only these univariate approaches will be presented here.

Surface types were not repeated over time (only the panels were), therefore, the repeated design was not appropriate at the surface type scale. An analysis of variance on the surface types effect (1 to 27 ) nested in the 8 panel types ( $A$ to $H$ ) was then used for each sampling period (March, June and September). With such large sample sizes $(n=864$ in March and $n=1152$ in June and September), tests of normality and homogeneity are often significant even when only small deviations occur. Normality of the residuals was not respected in March and September despite low skewness values ( 0.42 and 0.45 respectively), and variances were not homogeneous for any of the sampling periods. Hence, we performed the same analyses of variance on rank transformed data and compared the results with the parametric procedure. This procedure is equivalent to applying a nonparametric Friedman statistic with panel types as blocks. Since the statistical results were similar $(\alpha=0.05)$ only the parametric analyses will be shown (Conover 1980).

Multiple comparisons using the Least-squares means method (LSmeans, SAS software; SAS 1989) were applied with probability levels divided by the number of degrees of freedom (Bonferroni correction). In short, the LS means are pairwise $t$ tests that compare adjusted means and use the mean square error as the error term. By using LSmeans it is possible to compare differences between each level of one factor against each level of another factor.

In addition to the ANOVAs, contingency tables were used to test if the occurrence of the different species are the same for the 8 panel types. The log-likelihood ratio statistic $G$ (Zar 1984) was calculated for each month. Once the $G$ statistics were significant, a cell deviate $(Z)$ indicated which cells from the contingency table were significantly different from their expected frequency, according to Legendre \& Legendre (1984, p. 186; adapted from Neu et al. 1974).

\section{RESULTS}

\section{Species composition}

In March, the mean diversity was very low $\left(\bar{H}^{\prime}=\right.$ 0.64 ). Among the 7 species settled on the panels, the hydroid Tubularia crocea accounted for $81.6 \%$ of occurrences (Fig. 3) and the low diversity reflected the dominance of this species. In June, higher diversity values $\left(\bar{H}^{\prime}=2.47\right)$ were due to more even occurrences among the 15 species observed compared to species present in September $(n=20)$ and January ( $n$ $=22$ ). In fact, in June, the 5 most abundant species 
accounted for $79.5 \%$ of total occurrences, compared to over $90 \%$ at the other sampling periods. The community was different for each sampling period. Dominant species (by abundance) were: the hydrozoan Tubularia crocea in March, the bryozoan Bugula neritina in June, 2 bivalves, Crassostrea virginica and Ostrea equestris, (species non-differentiated because of the too-small size of most individuals) in September, and an ascidian, Styela plicata, in January. From June onwards, Schizoporella unicornis, an encrusting bryozoan, covered a large part of the substrata but was frequently overgrown by bivalves, ascidians and other species.

In March, only panel type A had higher occurrences than expected for Balanus sp. and Obelia sp. under the hypothesis of equal species distribution between the 8 panel types (Table 1). All other significant frequencies observed in March were lower than expected, e.g. Tubularia crocea on panel A and Balanus sp. and Obelia sp. on panel G. In June, Balanus sp. had the same distribution as in March, with higher abundance on panel $\mathrm{A}$ and lower than expected on panels including the $1 \mathrm{~mm}$ scale $\mathrm{F}$ and $\mathrm{H}$. In contrast, Schizoporella unicornis was found mostly on panel $\mathrm{E}$, which included a $1 \mathrm{~mm}$ scale, and was significantly less abundant on panel types $C$ and $D$, which did not have this scale. In September, the 2 dominant species had opposite patterns of occurrence: the ascidian Styela plicata was more frequent than expected on panel type $A$ and less frequent than expected on panel type $\mathrm{G}$ while the oysters Crassostrea virginica/Ostrea equestris were found more frequently on panel type $G$ and less frequently on panel type A. S. unicornis, as in June, was found mostly on panel type $E$, and less than expected on panels C, D and G. In January, patterns of species were more variable. The occurences of the asciadian Styela

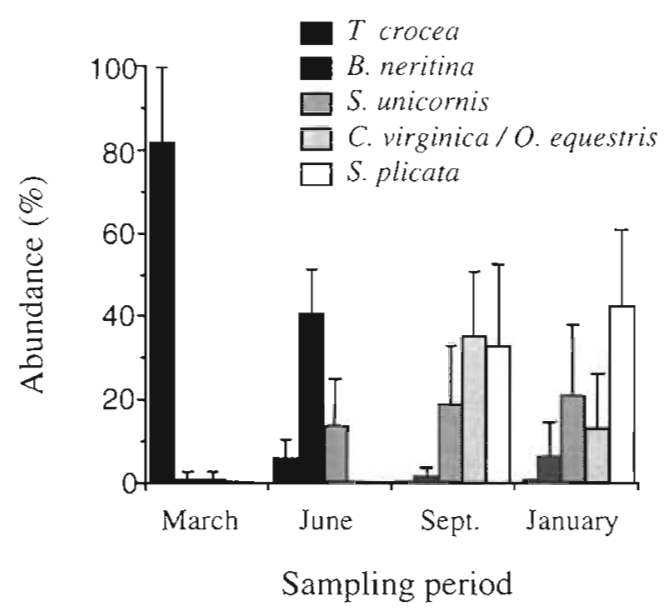

Fig. 3. Dominance ( $\% \pm$ STD, $n=64)$ by sampling period for the 5 dominant species plicata, the most abundant species, were higher than expected on panel types B, C and D (2nd order of complexity), and lower than expected on panels of the $3 \mathrm{rd}$ order of complexity, E and F. Thus, the sum of results indicated that the patterns of occurrence as related to the panel type were species dependent.

\section{Whole panels: complexity effects}

\section{Abundance}

As expected, among the factors examined, time had the most important effect on abundance $(F=887.6$, $p=0.0001$, Table 2). Changes with time were considerable. Mean percentages of about $40 \%$ were observed in March, $70 \%$ in June and 110\% in September and January (Fig. 4). Recruitment was also significantly influenced by the panel type ( $F=12.52$, $p=0.0001$ ) and this effect varied with time (as indicated by the significant interaction term; $F=6.62, \mathrm{p}=$ 0.0001 ). There was no significant line effect (random factor; Table 2). Effects due to the significant interaction $(F=3.21, \mathrm{p}=0.0001)$ between time and the supporting frame (random factor) were removed from the experimental error by the design. Multiple comparisons carried out within panel types for each sampling period (Table 3a, column 1) indicate that abundances were significantly lower in March than in June (except for panels $G$, not significant), which were lower than in September and January. Significant differences in abundance levels among panel types within time (Table $3 a$, column 2) were found only in March and June on panels which included the $1 \mathrm{~mm}$ scale ( $\mathrm{B}, \mathrm{E}, \mathrm{F}, \mathrm{H}$, in bold; Table 3). These $1 \mathrm{~mm}$ panels had significantly lower abundances than the other panels. In March, within each of the 'with and without $1 \mathrm{~mm}$ ' groups, abundance on panels decreased with the order of complexity. Within each group, panels that included the $10+100 \mathrm{~mm}$ scales (panels $G$ and $H$ ) exhibited highest abundances (3rd and 4 th order of complexity), followed by panels with the $10 \mathrm{~mm}$ scale (panels $C$ and $E$ ) and by panels with the $100 \mathrm{~mm}$ scale (panels D and F) (3rd and 2nd order of complexity). Lower abundances occurred on panels $A$ and $B$, those without 10 or $100 \mathrm{~mm}$ grooves and of 2 nd and 1 st order of complexity. The correction used is very conservative and had differences been observed at $\alpha=0.024$ instead of $\alpha=0.0071$, abundances on panels $\mathrm{G}$ would have been significantly higher than on panels C, D, A and differences between $H$ and $E, F, B$ would have reached significance (Table $3 \mathrm{a}$, column 2). This suggests that there was an overall positive effect on abundance at the $0+$ $10+100 \mathrm{~mm}$ scales in addition to the most important 


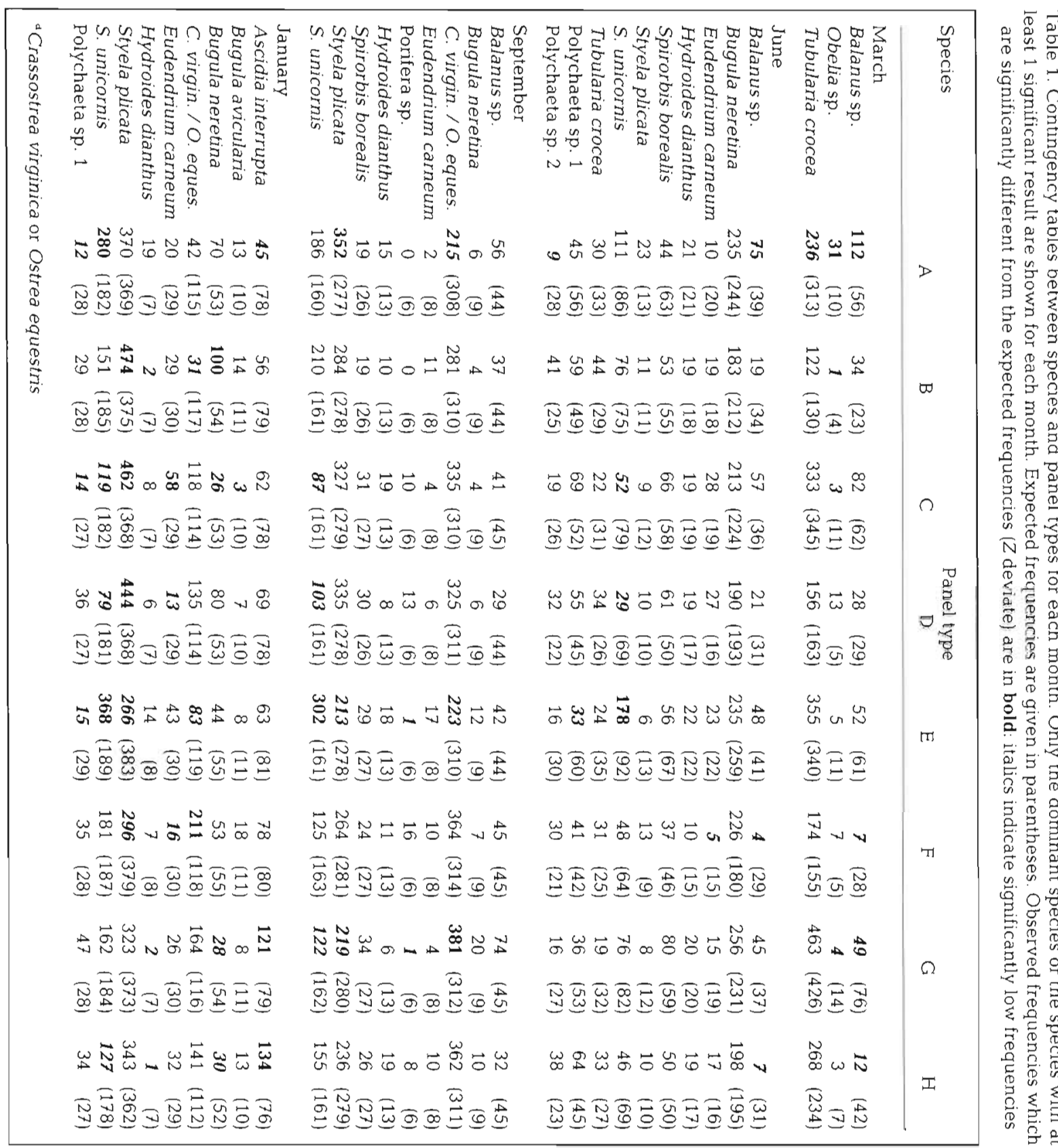


Table 3. Least-square means comparisons for the interaction between panel types $(A, B)$ and time. Panels in bold include scale of $1 \mathrm{~mm}$ for abundance and scale of $100 \mathrm{~mm}$ for diversity. Groups underlined are not significantly different. Probability levels were corrected by the degrees of freedom: $\alpha=$ 0.0167 for time within panel type comparisons; $\alpha=0.0071$ for panel type within-time comparisons. $\mathrm{Ma}=$ March, Ju = June, $\mathrm{Se}=$ September, $\mathrm{Ja}=$ January

\begin{tabular}{|c|c|c|}
\hline $\begin{array}{l}\text { Decreasing time } \\
\text { within panel types }\end{array}$ & \multicolumn{2}{|c|}{$\begin{array}{l}\text { Decreasing panel } \\
\text { types within time }\end{array}$} \\
\hline \multicolumn{3}{|l|}{ Abundance } \\
\hline A Ja Se Ju Ma & March & $G \subseteq D A \underline{E} F B$ \\
\hline B Ja Se $\underline{\mathrm{Ju}} \underline{\mathrm{Ma}}$ & & \\
\hline C $\underline{\text { Se Ja }} \underline{\text { Ju }} \underline{M a}$ & June & $D \underline{\mathrm{A}} \underline{\mathrm{G}} \subseteq \underline{\mathrm{B}} \underline{\mathrm{H}} \mathrm{E}$ \\
\hline $\mathrm{D} \underline{\mathrm{Ja}} \mathrm{Se} \underline{\mathrm{Ju}} \underline{\mathrm{Ma}}$ & & \\
\hline E $\underline{\mathrm{Ja}} \quad \mathrm{Se} \quad \underline{\mathrm{Ju}} \underline{\mathrm{Ma}}$ & September & $\underline{C} F$ D E H G A \\
\hline$F \quad \mathrm{Ja}$ Se $\underline{\mathrm{Ju}} \underline{\mathrm{Ma}}$ & & \\
\hline G Ja Se Ju Ma & January & $\mathrm{F} D \mathrm{D} G \mathrm{~B} A \mathrm{CH}$ \\
\hline H Ja Se Ju Ma & & \\
\hline \multicolumn{3}{|l|}{ Diversity } \\
\hline A Ju Ja Se Ma & March & $A E C B D G F H$ \\
\hline$B \quad \underline{J u}$ Se Ja Ma & & \\
\hline C Ju Ja Se Ma & June & $C B G E H A D F$ \\
\hline D Ju Se Ja Ma & & \\
\hline E Ju Ja Se Ma & September & $\underline{H} D F \underline{G} E B C A$ \\
\hline F $\underline{\mathrm{Ja}} \underline{\mathrm{Ju}}$ Se $\underline{\mathrm{Ma}}$ & & \\
\hline $\mathrm{G} \underline{\underline{J u}} \underline{\mathrm{Ja}} \mathrm{Se} \underline{\mathrm{Ma}}$ & January & $\underline{F} \mathbf{H} \mathrm{D} E A C B$ \\
\hline H Ju Ja Se Ma & & \\
\hline
\end{tabular}

negative effect of $1 \mathrm{~mm}$ grooves. However, this $0+10$ $+100 \mathrm{~mm}$ scale effect was not observed in the subsequent months.

In summary, panels without $1 \mathrm{~mm}$ grooves supported higher abundances compared to others but only in the 2 first sampling periods (March and June), when space on the panels (<70\% coverage) was not yet a limiting factor. As the abundance of organisms increased $(\sim 110 \%$ in September and January) the $1 \mathrm{~mm}$ grooves negative effect on abundance was no longer detected. In March, in addition to the $1 \mathrm{~mm}$ effect, higher abundances were observed on panels which included scales of $0+10+100 \mathrm{~mm}$.

\section{Diversity}

Diversity changed over time and with panel type (significant interaction, $F=3.95, \alpha=0.0001$, Table 2). In March (2 mo after immersion), diversity was lower than at any other period $\left(\bar{H}^{\prime}=0.64\right.$, Fig. 4 \& Table $3 b$, column 1). In June, panels without the $100 \mathrm{~mm}$ scale (panels A, B, C, E) exhibited significantly higher diversity than during the subsequent 2 sampling periods $\left(\vec{H}^{\prime}>2.4\right.$, Fig. 4 \& Table 3 b, column 1). At the beginning of the experiment, diversity was higher on the less complex surfaces and the opposite pattern. was observed in January; no detectable effect was observed during the transition period (June and September) (Table 3b, column 2 \& Fig. 4). Panels with $100 \mathrm{~mm}$ crevices (panels D, F, G, H) showed lower diversity than other panel types in March, whereas in January significantly higher diversity was observed on panel types $\mathrm{F}, \mathrm{H}, \mathrm{G}$ compared to panel types $\mathrm{E}, \mathrm{A}$, $C, B$. Diversity on panel type $D$ was not significantly higher than on panels E, A, C, B though the mean value was higher.

In summary, diversity was low in March for all panel types, with significantly lower diversity on panels that included the $100 \mathrm{~mm}$ scale compared to other panel types. The opposite pattern was found in January 1992 with highest diversity associated with the $100 \mathrm{~mm}$ scale. Over the year, diversity was highest in June.
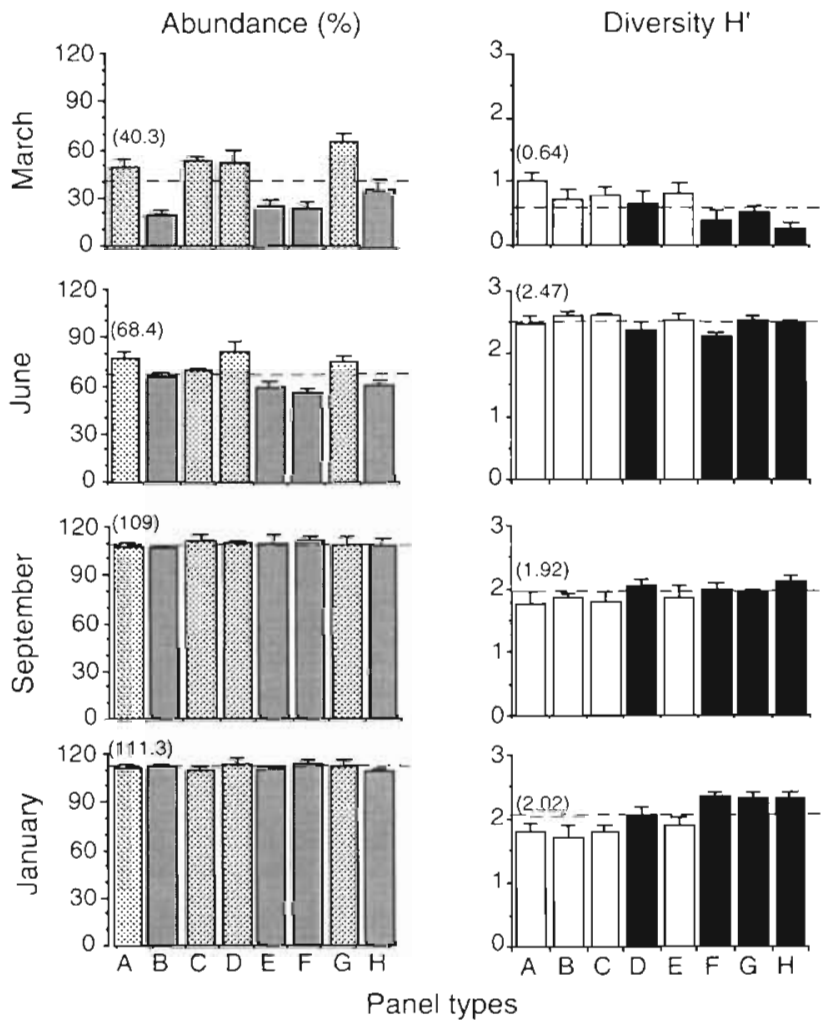

Fig. 4. Influence of time and panel types on percent cover and diversity $(\vec{X} \pm \mathrm{SE} ; \mathrm{n}=8)$. Dashed lines and parentheses are the mean for each period. Abundance: Panels with ( $\square$ ) and without (留) $1 \mathrm{~mm}$ scale; Diversity: Panels with (ם) and without ( $\square$ ) $100 \mathrm{~mm}$ scale 
Table 4. ANOVA for the surface types effect ( 1 to 27 ) nested in the 8 panel types (Pt: A to H). The 64 panels were arranged in a latin square design with supporting frame $(F)$ and lines ( $L$ ) as nuisance variables. Panels (nested in $F, L$ and $P t$ ) are random factor. Probabilities less than 0.05 are significant (in bold). The degree of freedom for the error term is higher in June and September than in March because of the higher number of samples taken for the surfaces inside the $100 \mathrm{~mm}$ crevices (see 'Methods' for explanation). Significant probabilities are in bold

\begin{tabular}{|c|c|c|c|c|}
\hline Source of variation & $\mathrm{df}$ & MS & $F$ & $\mathrm{p}$ \\
\hline \multicolumn{5}{|l|}{ March } \\
\hline Panel types & 7 & 550.4 & 9.01 & 0.000 \\
\hline Lines & 7 & 24.1 & 0.43 & 0.876 \\
\hline Supporting frame & 7 & 112.6 & 2.02 & 0.073 \\
\hline Panels (Pt $\times F \times L)$ & 42 & 59.0 & 3.47 & 0.000 \\
\hline Surface types $(\mathrm{Pt})$ & 19 & 74.8 & 4.39 & 0.000 \\
\hline Panels $\times$ Surf. types $(\mathrm{Pt} \times \mathrm{F} \times \mathrm{L})$ & 133 & 17.0 & 1.51 & 0.001 \\
\hline Error & 648 & 11.3 & & \\
\hline \multicolumn{5}{|l|}{ June } \\
\hline Panel types & 7 & 305.9 & 8.24 & 0.000 \\
\hline Lines & 7 & 30.1 & 0.93 & 0.494 \\
\hline Supports & 7 & 72.0 & 2.22 & 0.049 \\
\hline Panels (Pt $\times F \times L)$ & 42 & 35.5 & 3.09 & 0.000 \\
\hline Surface types $(\mathrm{Pt})$ & 19 & 71.7 & 6.24 & 0.000 \\
\hline Panels $\times$ Surf. types $(\mathrm{Pt} \times \mathrm{F} \times \mathrm{L})$ & 133 & 11.5 & 1.00 & 0.484 \\
\hline Error & 936 & 11.5 & & \\
\hline \multicolumn{5}{|l|}{ September } \\
\hline Panel types & 7 & 22.7 & 0.73 & 0.651 \\
\hline Lines & 7 & 63.4 & 2.37 & 0.038 \\
\hline Supports & 7 & 41.9 & 1.57 & 0.172 \\
\hline Panels (Pt $\times F \times L)$ & 42 & 29.7 & 4.00 & 0.000 \\
\hline Surface types $(P \mathrm{t})$ & 19 & 16.5 & 2.17 & 0.006 \\
\hline Panels $\times$ Surf types $(\mathrm{Pt} \times \mathrm{F} \times \mathrm{L})$ & 133 & 7.6 & 1.20 & 0.076 \\
\hline Error & 936 & 6.4 & & \\
\hline
\end{tabular}

Only the surface types ( 1 to 27 ) within the 8 panel types were interpreted in the nested ANOVAs, since all other effects were already analysed with the whole panel data.

The surface type effects on abundance nested within the 8 panel types were significant for all sampling periods (Table 4; March, $F=4.39, \mathrm{p}=$ 0.0001 ; June, $F=6.24, p=0.0001$; September, $F=2.17, \mathrm{p}=0.0057$ ). In March, significant interaction occurred between surface types and the random factor panels $(F=1.51$, $\mathrm{p}=0.0006$ ). This interaction was not interpreted further due to the randomness of the interaction (Milliken \& Johnson, 1992). Multiple comparisons of abundances among surface types (Table 5) performed within panel types showed that, in March, when differences were significant, the highest abundance usually occurred outside the $10 \mathrm{~mm}$ crevices. Abundance order for the surface types given in Fig. 1 as follows: $C$ panels, surfaces $4>5$; E panels, $8-9>10-11 ; G$ panels, $16-18>17-19$; $\mathrm{H}$ panels, 25-21-20 > other surfaces. In June, the pattern was different to that in March. Higher abundances were usually observed outside, rather than inside, the $100 \mathrm{~mm}$ crevices

\section{Surface types: heterogeneity effects}

Diversity was not calculated from each surface type as it represented a very small area $\left(20 \mathrm{~cm}^{2}\right)$. Therefore, for this unit of sampling, the scale of heterogeneity effect was analysed only for the variable abundance. (with the exception of surface numbers in parentheses which follow) but only for panels with complexity levels 3 or 4 . Abundance order for surfaces as defined in Fig. 1 for June were as follows: $F$ panels, surfaces $13-12-(15)>14 ; \mathrm{G}$ panels, $16-17>18-19 ; \mathrm{H}$ panels, 21-23>27-24-26. In September, only panel types F, G

Table 5. Least-squares means comparisons among surface types ( 1 to 27) within panel types ( $\mathrm{B}$ to $\mathrm{H}$ ). Surface types are in decreasing order of the mean, and groups underlined are not significantly different. Probability levels were corrected by the degrees of freedom within each panel type

\begin{tabular}{|c|c|c|c|}
\hline Panel type & March & June & September \\
\hline B & 32 & $\underline{32}$ & $\underline{23}$ \\
\hline $\mathrm{C}$ & 45 & $5 \underline{4}$ & $\underline{54}$ \\
\hline D & $\underline{6} \underline{z}$ & 67 & 67 \\
\hline $\mathrm{E}$ & 981011 & 911810 & 810119 \\
\hline $\mathrm{F}$ & 12151314 & $\underline{131215} \underline{14}$ & $\underline{1514} \underline{1213}$ \\
\hline $\mathrm{G}$ & 16181719 & $1617 \quad 1819$ & $17 \quad 18 \quad 16 \quad 19$ \\
\hline $\mathrm{H}$ & $\underline{2521202423222627}$ & 2123252022272624 & 2220232427212526 \\
\hline
\end{tabular}


and $\mathrm{H}$ showed differences among surface types. On panels F, abundances on surface 15, inside the $100 \mathrm{~mm}$ crevices, were higher than on surface 13, outside these crevices. The opposite was observed in June. For panel types $\mathrm{G}$ and $\mathrm{H}$, although differences in abundance were less pronounced in September than in June, the pattern of distribution was similar between the 2 months, with abundances on surfaces $17>19$ (panels $G$ ) and those on surface $22>24-27$ (21) -25 and 26 on panels $H$. There was a tendency for abundances to be higher on surfaces outside the $100 \mathrm{~mm}$ crevice than on surfaces inside the $100 \mathrm{~mm}$ crevice, apart for surface numbers in parentheses.

In summary, higher abundances were observed outside the $10 \mathrm{~mm}$ crevices in March and outside the $100 \mathrm{~mm}$ crevices in June and September, except for the $F$ panels. Indeed, from June onwards, differences in abundance were only detected on more complex panels including the $100 \mathrm{~mm}$ scale (panel types F, G and $\mathrm{H})$. Moreover, as observed for whole panels (Fig. 4), higher abundances on panels with no $1 \mathrm{~mm}$ scale $(A, C, D, G)$ were observed for March and June (Fig. 5).

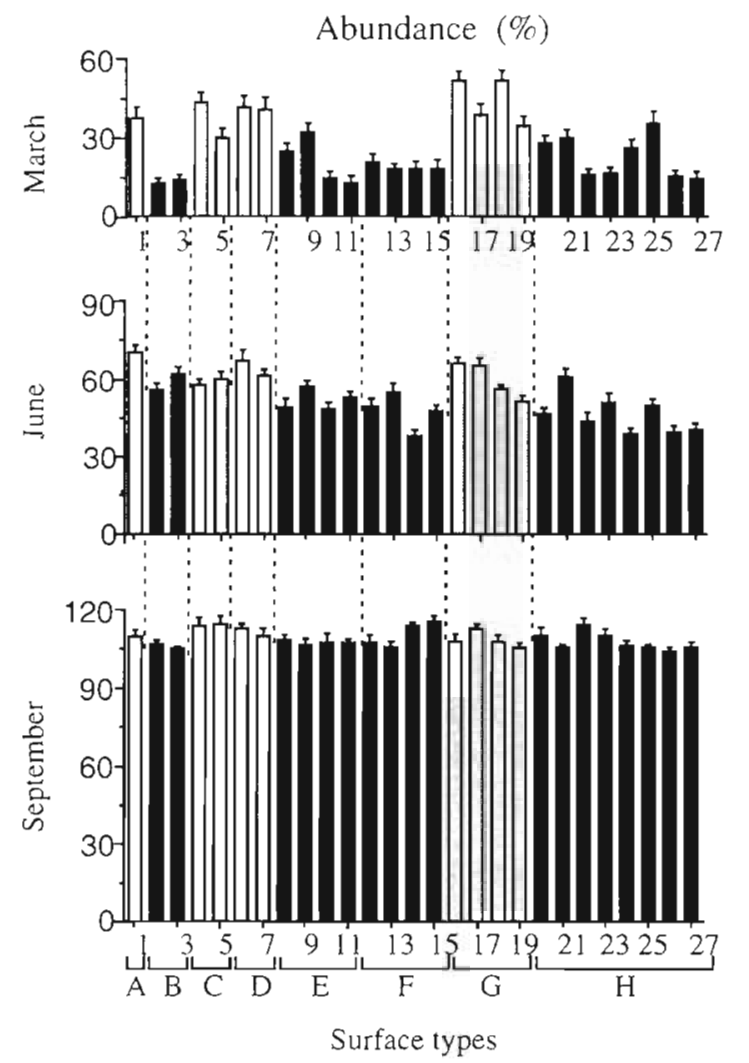

Fig. 5. Influence of time and surface types (1 to 27) within panel types $(A$ to $H)$ on the percent cover $(\bar{x} \pm S E ; n=8)$ Dark and light bars are for panels with (ם) and without (ㅁ) $1 \mathrm{~mm}$ scale

\section{DISCUSSION}

In this study, panel complexity was not the major factor structuring the community. At the scale of the whole panel, results clearly showed that the $1 \mathrm{~mm}$ heterogeneity scale was the dominant factor influencing abundances negatively. Experimental studies using 3-D artificial structures found that passive settlement processes (i.e. hydrodynamics) were sufficient to explain the recruitment patterns of various species at scales greater than $3 \mathrm{~cm}$, but at smaller scales (ca $1 \mathrm{~mm}$ ) results of these experiments could not reject hypotheses for active larval and/or postsettlement exploration of the substratum (Harvey \& Bourget 1997, Bourget \& Harvey 1998). Similar results at the $1 \mathrm{~mm}$ substratum heterogeneity scale were also observed in the laboratory (Harvey \& Bourget 1997). Even though the importance of spatial scales has been recognized for many years, with active and passive processes predominating at different spatial scales (Butman 1987, Bourget 1988, Levin 1992), our study indicates the specific importance of the $1 \mathrm{~mm}$ scale not only during the larval settlement phase but also during the subsequent development and maturation of the community.

A positive influence of complexity on abundance was observed in March only, early in the development of the community. This effect was no longer detected after important overgrowth occurred and space became a limiting factor (from June onward). In fact, no differences in total abundance were observed between September and January. By September, maximum abundance was reached and no more significant epizooic colonization occurred. However, although total abundance remained the same, major changes in species composition and diversity occurred and, as expected, highest diversity was observed in the intermediate stage of community development (June). Changes in diversity were related mainly to the $100 \mathrm{~mm}$ heterogeneity scale, regardless of the complexity level.

Hydrodynamic processes at heterogeneity scales 1 , 10 and $100 \mathrm{~mm}$ were examined by Grégoire et al. (1996) using inert particles (PVC) in a laboratory flume. The same panels and sampling units (i.e. transects of $1 \times 200 \mathrm{~mm}$ ) were used in both experiments. Grégoire et al. (1996) showed that particle density (per $\mathrm{cm}^{2}$ ) decreased with increasing panel complexity. The opposite pattern was observed in March inside the $1 \mathrm{~mm}$ scale, suggesting that larval behaviour was involved in settlement selection site. Moreover, laboratory experiments found that the $1 \mathrm{~mm}$ crevice, when alone on a panel, significantly enhanced the density of 'settled' particles whereas the density decreased on panels with only the 10 and $100 \mathrm{~mm}$ crevices, a pattern 
precisely the opposite of what was observed in our experiment.

Using identical panels in short-term field experiments (d) in Beaufort, Lemire \& Bourget (1996) found that Balanus sp. larvae settled predominantly on panels which did not include the $1 \mathrm{~mm}$ scale whereas Tubularia sp. larvae (a hydrozoan) selected the most complex panel type and generally settled on the most exposed surfaces. In a northern young epibenthic community that settled on similar panels at St. Andrews, New Brunswick, Canada, Bourget et al. (1994) found no effects of complexity on diversity nor on abundance (percent cover) within the first 3 mo of community development. However, the $1 \mathrm{~mm}$ scale was colonized to a greater degree than other scales in the first month of development, and 2 mo later the percent cover was greater in the $100 \mathrm{~mm}$ crevices than on other surface types. Thus, their results showed that mean diversity and total cover were affected differentially by the scales of heterogeneity depending on the species. These combined results, in addition to observed patterns of occurrence between species and panel types in this study (Table 1), suggest that larval behaviour (i.e. microhabitat selection) is involved in the settlement process despite local hydrodynamic conditions, and that microhabitat selection is species dependent. Passive settlement by hydrodynamics alone cannot explain the small-scale distribution of organisms on these artificial substrata.

For a current velocity of $5.75 \mathrm{~cm} \mathrm{~s}^{-1}$, the mean velocity observed at our field site by Lemire \& Bourget (1996), Reynolds numbers (Re), which characterized the flow near the 3 crevice sizes of 1,10 and $100 \mathrm{~mm}$, are respectively 49.5, 498 and 4980 . Reynolds numbers were calculated as $\operatorname{Re}=u d / v$, where $u$ is the flow velocity $\left(5.75 \mathrm{~cm} \mathrm{~s}^{-1}\right), d$ is the depth of the crevices (effective depths were $0.866,8.66$ and $86.6 \mathrm{~mm}$ because the crevice sizes 1,10 and $100 \mathrm{~mm}$ correspond to the hypotenuse of the crevices), and $v$ is the sea water kinematic viscosity $\left(0.01 \mathrm{~cm}^{2} \mathrm{~s}^{-1}\right)$. The dynamics of boundary layer flow around the $V$-shaped cavities of the experimental panels and the critical zone of $\mathrm{Re}$ numbers where vortice shedding is stable are not known. However, for a cylindrical structure, important. changes in flow pattern appear with $\mathrm{Re}>40$, in which a series of periodic vortices (called the Karman vortex street; Anderson \& Charters 1982, Shimeta \& Jumars 1991) are formed. Those vortices may induce larval retention or increase impingement of larvae near some parts of the structure (Harvey et al. 1995). With more complex V-shaped grooves, patterns of flow dynamics are difficult to predict, and a study of flow near the grooves would be useful to interpret the results. Nevertheless, as the major influence on the percent cover observed is lower abundance associated with the $1 \mathrm{~mm}$ crevice, it is possible that for this size of crevice flow is laminar; this could explain the low abundance observed, no retention zone being formed by hydrodynamics. However, Grégoire et al. (1996) found higher densities of inert particles in the $1 \mathrm{~mm}$ crevices, which supports the hypothesis of active avoidance of small crevices by larvae under field conditions. Behaviour of species avoiding the $1 \mathrm{~mm}$ crevices could explain the difference between flume and field results.

In addition to the hydrodynamic retention process discussed above, predation could be a factor influencing diversity on the panels. However, we did not control for predation since control would be difficult without changing the local hydrodynamic flows. The $V$-shape in the panels may provide a refuge against predation and could be a factor increasing diversity on the panels. Indeed, this refuge effect may explain higher diversity associated with the $100 \mathrm{~mm}$ scale on the panels in January.

This experiment was equivalent to a pulse by contrast to a press experiment (Bender et al. 1984, Schmitz 1997). In the former, only the initial conditions are important for the experiment. By contrast, in a press experiment the conditions are maintained throughout the experiment. Our results showed a significant effect of heterogeneity well beyond 3 mo on community characteristics (diversity after 12 mo and abundance after $6 \mathrm{mo}$ ). Even if small scales cannot easily be observed when the layer of benthos became very dense (September onward) they might, for instance, facilitate the attachment of some species, create biotic heterogeneity, and impact on subsequent attachment and diversity. For example, either size and density of barnacles were shown to have an effect on the hydrodynamic regime over a population (Thomason et al. 1998). Since the object of the experiment was to examine community characteristics in a 'pulse experiment' we feel it important to include all results including those related to the building of biotic heterogeneity. The results obtained confirm the (direct or indirect) importance of small scales even after 1 yr.

In conclusion, early successional stages of the temperate community structure were significantly affected by both heterogeneity and complexity of the substratum. However, complexity is not the dominant factor influencing community structure. Indeed, heterogeneity scale of $1 \mathrm{~mm}$ was the dominant factor that significantly influenced abundances negatively, while changes in diversity were related mainly to the $100 \mathrm{~mm}$ scale of heterogeneity regardless of the complexity level. These results suggest that small-scale patterns of substratum heterogeneity and complexity must be considered when attempting to model the temporal development of epibenthic communities. 
Acknowledgements. We thank Dr D. Rittschof from the Duke Marine Laboratory, Beaufort, North Carolina, for the use of his raft and laboratory space, Dr Eric Holm for helpful comments and assistance, Dr W. Kirby-Smith for his help with species identification, C. Pearce, R. Sanchez, S. Asselin, D. Cloutier, G. Tardif, I. Tanguay, C. Legault and B. Boudreau for their help in the field and A. Ricciardi and C. Lovejoy for linguistic revisions and comments. Financial support was provided by grants from NSERC and FCAR to E.B. This study is a contribution to the program of GIROQ (Groupe interuniversitaire de recherches océanographiques du Québec).

\section{LITERATURE CITED}

Anderson SM, Charters AC (1982) A fluid dynamics study of seawater flow through Gelidium nudifrons. Limnol Oceanogr 27:399-412

Archambault P, Bourget E (1996) Scales of coastal heterogeneity and benthic intertidal species richness, diversity and abundance. Mar Ecol Prog Ser 136:111-121

Barnes H (1956) Surface roughness and the settlement of Balanus balanoides (L.). Arch Soc Zoo Bot Fenn Vanamo 10: $164-168$

Bender EA, Case TJ, Gilpin ME (1984) Perturbation experiments in community ecology: theory and practice. Ecology 65:1-1.3

Bergeron P, Bourget E (1986) Shore topography and spatial partitioning of crevice refuges by sessile epibenthos in an ice disturbed environment. Mar Ecol Prog Ser 28: $129-145$

Blanchard D, Bourget E (1999) Scales of coastal heterogeneity: Influence on intertidal community structure. Mar Ecol Prog Ser 179:163-173

Bourget E (1988) Barnacle larval settlement: the perception of cues at different spatial scales. In.: Chelazzi $G$, Vannini $M$ (eds) Behavioral adaptation to intertidal life. Plenum Press, New York, p 153-172

Bourget E, Harvey M (1998) Spatial analysis of recruitment of marine invertebrates on arborescent substrata. Biofouling 12:45-55

Bourget E, DeGuise J, Daigle G (1994) Scales of substratum heterogeneity, structural complexity, and the early establishment of a marine epibenthic community. J Exp Mar Biol Ecol 181:31-51

Brault S, Bourget E (1985) Structural changes in an estuarine subtidal epibenthic community: biotic and physical causes. Mar Ecol Prog Ser 21:63-73

Butman CA (1987) Larval settlement of soft-sediments invertebrates: the spatial scales of pattern explained by active habitat selection and the emerging role of hydrodynamical processes. Oceanogr Mar Biol Annu Rev 25:113-165

Chabot R, Bourget $E$ (1988) Influence of substratum heterogeneity and settled barnacle density on the settlement of cypirs larvae. Mar Biol 97:45-56

Connell JH (1975) Some mechanisms producing structure in natural communities: a model and evidence from field experiments. In: Cody ML, Diamond JM (eds) Ecology and evolution of communities. Harvard University Press, Cambridge, p $460-490$

Connell JH (1983) On the prevalence and relative importance of interspecific competition: evidence from field experiments. Am Nat 122:661-696

Conover WJ (1980) Practical nonparametric statistics, 2nd edn. John Wiley, New York

Crisp DJ (1974) Factors influencing the settlement of marine invertebrate larvae. In: Grant PT, Mackie AM (eds)
Chemoreception in marine organisms. Academic Press, New York, p 177-265

Crisp DJ, Barnes H (1954) The orientation and distribution of barnacles at settlement with particular reference to surfacce culture. J Anim Ecol 23:142-162

Dayton PK (1984) Processes structuring some marine communities: are they general? In: Strong DR, Simberloff D, Abele LG, Thiestle AB (eds) Ecological communities: conceptual issues and the evidence. Princeton University Press, Princeton, p 181-197

Eckman JE (1983) Hydrodynamic processes affecting benthic recruitment. Limnol Oceanogr 28:241-257

Gaines SD, Bertness MD (1992) Dispersal of juveniles and variable recruitment in sessile marine species. Nature 360 : $579-580$

Girden ER (1992) ANOVA: Repeated measures. Sage University paper series. Quantitative Applications in the social Sciences, no. 84, Newbury Park, CA

Grégoire Y, Bourget E, Verrette JL (1996) Deposition of mimics of planktonic invertebrate larvae on simple and complex substrata in flume flows. Mar Ecol Prog Ser 135: $89-100$

Grosberg RK, Levitan DR (1992) For adults only? Supply-side ecology and the history of larval biology. Trends Ecol Evol $7: 130-133$

Harvey M, Bourget E (1997) Recruitment of marine inverteb:ates onto arborescent epibenthic stuctures: active and passive processes acting at different spatial scales. Mar Ecol Prog Ser 153:203-215

Harvey M, Bourget E, Ingram RG (1995) Experimental evidence of passive accumulation of bivalve larvae on filamentous epibenthic structures. Limnol Oceanogr 40: $94-104$

Hills JM, Thomason JC (1998) The effect of scales of surface roughness on the settlement of barnacle (Semibalanus balanoides) cyprids. Biofouling 12:57-69

Keough MJ, Downes BJ (1982) Recruitment of marine invertebrates: the role of active larval choices and early mortality. Oecologia 54:348-352

Le Fèvre J, Bourget E (1991) Neustonic niche for cirripede larvae as a possible adaptation to long-range dispersal. Mar Ecol Prog Ser 74:185-194

Le Fèvre J, Bourget E (1992) Hydrodynamics and behaviour: transport processes in marine invertebrate larvae. Trends Ecol Evol 7:288-289

Legendre L, Legendre P (1984) Écologie numérique. Tome 1, Le traitement multiple des données écologiques. Collection d'écologie 12. Masson, Paris, et les Presses de l'Université du Québec

Lemire $M$, Bourget $E$ (1996) Substratum heterogeneity and complexity influences micro-habitat selection of Balanus sp. and Tubularia crocea larvae. Mar Ecol Prog Ser 135: $77-87$

Levin SA (1992) The problem of pattern and scale in ecology. Ecology 73: 1943-1967

Lewin R (1986) Supply-side ecology. Science 234:25-27

Milliken GA, Johnson DE (1992) Analysis of messy data. Volune 1: Designed experiments. Van Nostrand Reinhold, New York

Miron G, Boudreau B, Bourget E (1995) Use of larval supply in benthic ecology: testing correlations between larval supp.y and larval settlement. Mar Ecol Prog Ser 124:301-305

Mullineaux LS, Butman CA (1991) Initial contact, exploration and attachment of barnacle (Balanus amphitrite) cyprids settling in flow. Mar Biol 110:93-113

Neu CW, Byers CT, Peek JM (1974) A technique for analysis of utilization-availability data. J Wild Manag 38:541-545 
Roughgarden J (1983) Competition and theory in commumity ecology. Am Nat 122:583-601

Roughgarden J, Gaines SD, Pacala SW (1987) Supply-side ecology: the role of physical transport processes. In: Gee JHR, Giller PS (eds) Organization of communities: past and present. Blackwell Scientific Press, London, p 491-518

SAS (1989) SAS Institute Inc. Software release 6.08. Cary, NC

Schmitz OJ (1997) Press perturbations and the predictability of ecological interactions in a food web. Ecology 78 : $55-69$

Schoener TW (1983) Field experiments on interspecific competition. Am Nat 122:240-285

Shimeta J, Jumars PA (1991) Physical mechanisms and rates of particle capture by suspension-feeders. Oceanogr Mar Biol Annu Rev 29:191-257

Thomason JC, Hills JM, Clare AS, Neville A, Richardson M

Editorial responsibility: Otto Kinne (Editor),

Oldendorf/Luhe, Germany
(1998) Hydrodynamic consequences of barnacle colonization. Hydrobiologia 375/376:191-201

Underwood AJ, Denlex EJ (1984) Paradigma, explanations and generalizations in models for the structure of intertidal communties on rocky shores: In: Strong DR, Simberloff $\mathrm{D}$, Abele LG, Thistle AB (eds) Ecological communities: conceptual issues and the evidence. Princeton Universtiy Press, Princeton, p 151-180

Underwood AJ, Chaprnan N.1G (1996) Scales of spatial patterns of distribution of intertidal invertebrates. Oecologia $107: 212-224$

Walters LJ (1992) Post-settlement success of the arborescent bryozoan Bughula neritina (L.): the importance of structural complexity. J Exp Mar Biol Ecol 164:55-71

Zar JH (1984) Biological analysis, 2nd edn. Prentice-Hall, Englewood Cliffs, NJ

Submitted: September 1, 1998; Accepted: June 8, 1999

Proofs received from author(s): November 9, 1999 